\title{
Voltammetric Studies of Catechol Behavior in Presence of 4,4'- bipyridine via Convolutive Voltammetry, Chronoamperometry and Digital Simulation
}

\author{
A.A.Al-Owais ${ }^{1}$ and I.S.El-Hallag ${ }^{2, *}$ \\ ${ }^{1}$ Chemistry Department, Faculty of Science, King Saud University, Reyad, Sa \\ ${ }^{2}$ Chemistry Department, Faculty of Science, Tanta University, Tanta, Egypt \\ *E-mail: $\underline{\text { i.elhallag@yahoo.com }}$
}

doi: $10.20964 / 2021.06 .58$

Received: 18 February 2021 / Accepted: 5 April 2021 / Published: 30 April 2021

\begin{abstract}
Voltammetric studies of catechol behavior with and without 4,4'-bipyridine was performed via cyclic, convolutive voltammetry, chronoamperometric and digital simulation at gold electrode in $0.5 \mathrm{M} \mathrm{KNO}_{3}$ aqeous solution as background electrolyte. This study aim o to explain the catechol behavior in case of existence of 4,4'-bipyridine in $0.5 \mathrm{M} \mathrm{KNO}_{3}$ aqueous solution. Voltammetric studies revealed that the electrooxidative process of catechol yield active, o-benzoquinone as intermediate, which reacts with 4, 4'-bipyridine to produce the derivative of catechol substance. The electrochemical parameters were determined experimentally and confirmed via generation of theoretical voltammograms. Based on the voltammetric behavior of the investigated compound, the electrode mechanism was proposed.
\end{abstract}

Keywords: Convolutive voltammetry, EC process, Chronoamperometry, 4, 4-bipyridine

\section{FULL TEXT}

(C) 2021 The Authors. Published by ESG (www.electrochemsci.org). This article is an open access article distributed under the terms and conditions of the Creative Commons Attribution license (http://creativecommons.org/licenses/by/4.0/). 